Dokuz Eylül Üniversitesi-Mühendislik Fakültesi

Fen ve Mühendislik Dergisi

Cilt 19, Sayı 57, Eylül 2017
Dokuz Eylul University-Faculty of Engineering Journal of Science and Engineering Volume 19, Issue 57, September 2017

DOI: $10.21205 /$ deufmd.2017195766

\title{
Load Dispatch for a Power System in terms of Economy and Environment by Using VIKOR Method
}

\author{
Özge Pınar AKKAŞ ${ }^{* 1}$, Yağmur ARIKAN ${ }^{1}$, Ertuğrul ÇAM ${ }^{1}$
}

${ }^{1}$ Kirıkkale University, Faculty of Engineering, Electrical-Electronics Engineering Department, 71450, Kırıkkale

(Alınıș / Received: 23.06.2017, Kabul / Accepted: 21.08.2017, Online Yayınlanma / Published Online: 20.09.2017)

Keywords

Economic

Dispatch,

Environmental

Dispatch,

Optimization,

Emission,

VIKOR

\begin{abstract}
Load dispatch considering economy and environment is an important issue at power systems. Economic load dispatch aims to generate demanded energy with minimum cost. It dispatches the load among generators by decreasing fuel cost. Otherwise, thermal plants are used commonly in the world to generate energy and they cause to environmental pollution. Energy generation with the most economic cost is good but protection of environment must be considered. Environmental load dispatch aims to generate demanded energy with minimum emission. It is significant for living in good health and clean environment. In this study, economic and environmental load dispatch problems are applied to a power system that consists of six generators to investigate cost and emission. VlseKriterijumska Optimizacija I Kompromisno Resenje (VIKOR) method is used for this study. VIKOR is one of the multi-criteria decision-making methods. It gives the most ideal solution for the problem.
\end{abstract}

VIKOR Yöntemi ile Güç Sistemi için Ekonomi ve Çevre Yönünden Yük Dağıtımı

\begin{abstract}
Anahtar Kelimeler Özet: Ekonomiyi ve çevreyi göz önünde bulundurarak yapılan yük
Ekonomik

Dağıtım,

Çevresel Dağıtım,

Optimizasyon,

Emisyon,

VIKOR

dağıtımı, güç sistemlerinde önemli bir konudur. Ekonomik yük dağıtımı, talep edilen enerjiyi minimum maliyet ile üretmeyi hedefler. Yükü, jeneratörler arasında yakıt maliyetini azaltacak şekilde dağıtır. Öte yandan, termik santraller enerji üretmek için dünyada yaygın olarak kullanılmaktadır ve çevre kirliliğine nedne olmaktadır. En ekonomik maliyet ile enerji üretmek iyidir fakat çevrenin korunması da dikkate alınmalıdır. Çevresel yük dağıtımı, talep edilen enerjiyi minimum emisyon ile üretmeyi hedefler. $\mathrm{Bu}$ durum sağlıklı olarak ve temiz bir çevrede yaşamak için önemlidir. Bu çalışmada, ekonomik ve çevresel yük dağıtımı problemleri, maliyet ve emisyonu incelemek için altı jeneratörden oluşan bir güç sistemine uygulanmıștır. $\mathrm{Bu}$ çalıșma için VlseKriterijumska Optimizacija I Kompromisno Resenje (VIKOR)
\end{abstract}


Ö. P. Akkaş et all. / Load Dispatch for a Power System in terms of Economy and Environment by Using VIKOR Method

yöntemi kullanılmıştır. VIKOR, çok kriterli karar verme yöntemlerinden birisidir. Problemler için en ideal çözümü vermektedir.

*Sorumlu Yazar: pozge.arslan@gmail.com

\section{Introduction}

Electric power systems have become complicated due to need of large energy system and privatization of the energy sector. Therefore, it is important to operate power systems economically and generate the energy with the cheapest cost. Operating planning is the important task to find minimum cost. Economic load dispatch problem minimizes the generation cost with meeting demand. It also satisfies the equality and inequality constraints.

The power plants based on fossil fuel are a significant source of power supply in the world. They are chosen due to being abundant on the earth and having ability to generate large amounts of electric power in any one location [1]. However, while energy is generated, environment must be considered because dangerous gases release to the air. Generators that use fossil resources forms particles that contains carbon dioxide, sulfur dioxide, and nitrogen oxide. The excessive increase in the amount of emissions causes to dangerous ecological effects. The resulting pollution affects the animals and plants as well as people. It also causes to global warming. It is significant to consider environment while generating energy for these reasons. Environmental load dispatch aims to reduce emissions.

For these reasons, firstly economic analysis and then environmental analysis are done for power systems. There are a lot of methods that have been used to solve economic and environmental load dispatch problems. Chen et all. provide a nonlinear fractional programming approach to solve the environmentaleconomic power dispatch problems in the thermal power dispatch systems [1]. They use IEEE 30-bus test system to show the effectiveness of their approach. Abdelaziz et all. have discussed an application of Flower Pollination Algorithm to solve Economic Load Dispatch and Combined Economic Emission Dispatch [2]. They have results for small and large scale power systems and consider valve loading effect. Bhattacharjee et all. have presented the solution for a nonlinear constrained multi objective of the economic and emission load dispatch problem with backtracking search optimization technique [3]. Rajan and Malakar solve Optimum Active Power Dispatch problem using Exchange Market Algorithm [4]. They develop the programs in MATLAB and test on standard IEEE 30 bus comprising of six thermal units. Fadıl and Urazel use an iterative solution method based on modified subgradient algorithm operating on feasible values (F-MSG) to solve environmental/economic power dispatch problem [5]. They demonstrate the technique on IEEE 30-bus power system and their method outperforms against the evolutionary methods in terms of solution time values. Rugthaicharoenchep and Thongkeaw solve economic load dispatch in test system of six-generation units with developing particle swarm optimization algorithm [6]. Sen and Mathur present a newly developed hybrid optimization algorithm named ACO-ABC-HS (Ant Colony Optimization-Artificial Bee Colony-Harmonic Search) for solving the problem of Economic Dispatch for a multi-generator system [7]. Dosoglu et all. presents Symbiotic Organisms Search (SOS) algorithm to solve economic emission load dispatch 
Ö. P. Akkaş et all. / Load Dispatch for a Power System in terms of Economy and Environment by Using VIKOR Method

problem for thermal generators in power systems [8]. Hota and Sahu develop a fuzzy based gravitational search algorithm to solve security constrained economic and environmental load disptch problems [9].

VIKOR method that is used in this study is a multi-criteria optimization technique and presents compromise solution for the problems. Bansal et all. identifies various sustainability indicators during the construction stage for elevated transportation corridors using fuzzy VIKOR technique [10]. Mohanty and Mahapatra propose VIKOR method to choose ergonomic office chair for improving the comfort level [11]. It is obtained that VIKOR method is not used about power systems. Therefore, it is decided to use VIKOR method in the solution of economic and environmental load dispatch problems. It is determined that which generator, how much energy should generate for economic and environmental dispatch. Thus, both economic and environmental load dispatch can be found in a simpler and better results than the other methods mentioned above.

\section{Problem Definition}

In this study, two competing functions that are fuel cost and amount of emission are tried to minimize under the conditions of satisfying equality constraint. Fuel cost is minimized for economic load dispatch problem and amount of emission is minimized for environmental load dispatch problem.

Economic load dispatch is formulated by considering the cost function. Each generator in the power system has cost function. The cost curves of the thermal power plants are approximately represented by a quadratic function that is shown in Equation 1.

$F($ total $)=\sum_{i=1}^{n} a_{i}+b_{i} P_{i}+c_{i} P_{i}^{2}$ where $F$ (total) is the total fuel cost $(\$ / h r), a_{i}, b_{i}$, and $c_{i}$ are the fuel cost coefficients of the $\mathrm{i}$-th generator, $\mathrm{n}$ is the number of generator in the power system and $\mathrm{P}_{\mathrm{i}}$ is the power generated by i-th generator.

Environmental load dispatch problem can be expressed as shown in Equation 2.

$E($ total $)=\sum_{i=1}^{n} f_{i}+e_{i} P_{i}+d_{i} P_{i}^{2}$

where $\mathrm{E}$ (total) is the amount of total emission $(\mathrm{kg} / \mathrm{hr}), \mathrm{d}_{\mathrm{i}}, \mathrm{e}_{\mathrm{i}}$, and $\mathrm{f}_{\mathrm{i}}$ are the $\mathrm{NO}_{\mathrm{x}}$ emission coefficients of the i-th generator, $\mathrm{n}$ is the number of generator in the power system and $\mathrm{P}_{\mathrm{i}}$ is the power generated by i-th generator.

There are some constraints while solving the power disptach problems. They are as follows [12]:

Power balance constraint: The total generated power should satisfy the total demand power and the transmission loss (if it is considered in the problem). It is shown in Equation 3.

$\sum_{i=1}^{n} P_{i}-P_{\text {loss }}=P_{D}$

where $\mathrm{P}_{\text {loss }}$ is the transmission loss and $P_{D}$ is the total demand power.

Generation limits: Each generator should generate power within lower and upper limits as shown in Equation 4.

$P_{i}^{\text {min }} \leq P_{i} \leq P_{i}^{\text {max }} \quad i \in\{1,2,3, \ldots, n\}$

where $P_{i}^{\min }$ is the minimum power that ith generator can produce and $P_{i}^{\max }$ is the 
maximum power that i-th generator can produce.

In this study, one equality constraint of power balance is considered as system constraint. The transmission losses are not considered in the problem. Therefore, total demand power must be equal to the total power generated by the power system.

In the solution of these problems, VIKOR method is suggested instead of many methods that are mentioned above.

\section{Material and Method}

In this study VIKOR method is used. It is a multi-criteria method developed by Serafim Opricovic in 1998. It solves a discrete multi-criteria problem with noncommensurable and conflicting area and determines a compromise solution for ranking and selecting considering conflicting criteria [13]. It helps the decision makers to reach a final solution.

The methodology of VIKOR method can be explained in the following steps:

Step 1: The best $\mathrm{f}_{\mathrm{i}}{ }^{*}$ and the worst $\mathrm{f}_{\mathrm{i}}$ values of all criterion functions are determined.

If the i-th function represents a benefit:

$f_{i}^{*}=\max f_{i j}, f_{i}^{-}=\min f_{i j}$

If the i-th function represents a cost:

$f_{i}^{*}=\min f_{i j}, f_{i}^{-}=\max f_{i j}$

where $f_{i j}$ is the related rating of the $i$-th criterion.
Step 2: The values of $S_{j}$ and $R_{j}$ are calculated. $S_{j}$ and $R_{j}$ are used to formulate ranking measure. The solution obtained by $\min S_{j}$ is with a maximum group utility and the solution obtained by $\min R_{j}$ is with a minimum individual regret of the opponent [14].

$S_{j}=\sum_{i=1}^{n} w_{i} \frac{\left(f_{i}^{*}-f_{i j}\right)}{\left(f_{i}^{*}-f_{\mathrm{i}}^{-}\right)}$

$R_{j}=\max \left(\sum_{i=1}^{n} w_{i} \frac{\left(f_{i}^{*}-f_{i j}\right)}{\left(f_{i}^{*}-f_{i}^{-}\right)}\right)$

where $\mathrm{w}_{\mathrm{i}}$ is the weight of criterion.

Step 3: $Q_{j}$ index values are calculated according to $S_{j}$ and $R_{j}$ :

$Q_{j}=v \frac{\left(S_{j}-S^{*}\right)}{\left(S^{-}-S^{*}\right)}+(1-v) \frac{\left(R_{j}-R^{*}\right)}{\left(R^{-}-R^{*}\right)}$

where $S^{*}=\min ^{j} S_{j}, S^{-}=\max ^{j} S_{j}, R^{*}=\min ^{j}$ $R_{j}, R^{-}=\max { }^{j} R_{j} . v$ refers to the weight for strategy that ensures maximum group benefit, (1-v) refers to the weight of minimum regret in dissent. The value of $\mathrm{v}$ changes between 0 and 1 . Generally, the value of $\mathrm{v}$ is taken as 0.5 .

Step 4: The calculated values of $Q_{j}, S_{j}$, and $R_{j}$ are ranked in decreasing order. $Q_{j}$ evaluation unit with the smallest value is expressed as the best option in the alternative group.

Step 5: Two conditions must be satisfied to accept the obtained results as valid. These conditions are:

Condition 1: Acceptable advantage: It states that there is significant difference between the best option and the option that is the closest one to the best option:

$Q\left(A^{2}\right)-Q\left(A^{1}\right) \geq D(Q)$

where $Q\left(A^{1}\right)$ is the best option, $Q\left(A^{2}\right)$ is the option that is the closest one to the 
Ö. P. Akkaş et all. / Load Dispatch for a Power System in terms of Economy and Environment by Using VIKOR Method

best option. $D(Q)=1 /(j-1)$ where $\mathrm{j}$ is the number of evaluation units.

Condition 2: Acceptable stability: $A^{1}$ option that has the best $\mathrm{Q}$ value must have the best score at least one of the $S$ value and $R$ value.

Whether one of the conditions are not satisfied, the compromise solution is recommended as follows:

$>$ If condition 2 is not satisfied, alternatives $\mathrm{A}^{1}$ and $\mathrm{A}^{2}$ are expressed.

$>$ If condition 1 is not satisfied, alternatives $A^{1}, A^{2}, \ldots, A^{N}$ for $N$ alternatives are expressed. $\mathrm{N}$ is the biggest value that satisfies the inequality

$\mathrm{Q}\left(\mathrm{A}^{\mathrm{N}}\right)-\mathrm{Q}\left(\mathrm{A}^{1}\right)<\mathrm{D}(\mathrm{Q})$.

In this study, 6 generators are determined as decision points for both economic and environmental dispatch problems. The fuel cost coefficients of the system $(a, b, c)$ are established as the factors that affect the decision points for economic dispatch problem and the $\mathrm{NO}_{\mathrm{x}}$ emission coefficients of the system $(d, e, f)$ are established as the factors that affect the decision points for environmental dispatch problem. The values of $f_{i}$ in the solution steps are determined by considering cost coefficients ( $a, b$, and $c$ ) for economic dispatch problem and emission coefficients (d,e, and f) for environmental dispatch problem.

\section{Results}

The economic and environmental dispatch problems are solved on the six generators test system. The data of fuel cost coefficients and $\mathrm{NO}_{\mathrm{x}}$ emission coefficients of the system is taken from study of Rughooputh [15]. The structure of the six generators test system is shown in Figure 1.

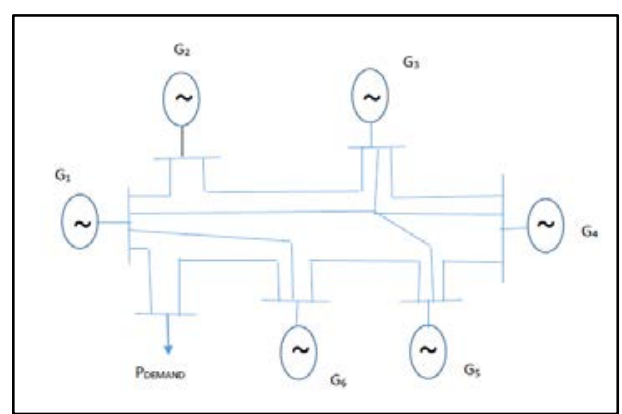

Figure 1. Structure of the test system

In the solution of economic dispatch problem, 6 generators are determined as decision points. The fuel cost coefficients of the system $(a, b, c)$ are established as the factors that affect the decision points. Firstly, values of $f_{i}$ are determined by considering cost coefficients (a,b, and $c)$. The decision matrix that consists of values of $f_{i}$ is obtained. While forming the decision matrix, the numbers from 1 to 10 are given as points to the elements of the matrix. The points are determined by considering the values of cost coefficients for each generator. For example, the minimum value of cost coefficient a is for Generator 2. It is benefit to take minimum value due to cost calculation. Therefore, Generator 2 takes the biggest point (10) among other generators for cost coefficient $a$. The maximum value of cost coefficient a is for Generator 5 so it takes the smallest point (1) among other generators for cost coefficient a. The decision matrix for economic dispatch problem is shown in Table 1. 
Ö. P. Akkaș et all. / Load Dispatch for a Power System in terms of Economy and Environment by Using VIKOR Method

Table 1. The values of fi for all criterion in economic dispatch problem

\begin{tabular}{cccc}
\hline Generators & $\mathrm{a}$ & $\mathrm{b}$ & $\mathrm{c}$ \\
\hline Generator-1 & 8 & 4 & 1 \\
Generator-2 & 10 & 1 & 2 \\
Generator-3 & 6 & 2 & 6 \\
Generator-4 & 4 & 6 & 4 \\
Generator-5 & 1 & 10 & 8 \\
Generator-6 & 2 & 8 & 10 \\
\hline
\end{tabular}

As seen in Table 1, the maximum valueof $f_{i}\left(f_{i}{ }^{*}\right)$ is 10 and minimum value of $f_{i}\left(f_{i^{-}}\right)$ is 1 . These values are taken in the calculations.

The values of $S_{j}, R_{j}$, and $Q_{j}$ that are mentioned in Step 2 and Step 3 are calculated by using Equation 6, Equation 7, and Equation 8. The weights of criterion are taken from the study [16]. In study [16], the values of criterion for the same power system that is used in this study are obtained by Analytical Hierarchy Process (AHP) method. According to it, the weights of criterion (cost coefficents a, b, c) are $0.08,0.20$ and 0.72 , respectively. The values of $S_{j}, R_{j}$, and $Q_{j}$ and order in economic dispatch problem are shown in Table 2 and Table 3 , respectively.

Table 2. The values of $S_{j}, R_{j}, Q_{j}$ in economic dispatch problem

\begin{tabular}{cccc}
\hline Generators & $\mathrm{S}_{\mathrm{j}}$ & $\mathrm{R}_{\mathrm{j}}$ & $\mathrm{Q}_{\mathrm{j}}$ \\
\hline Generator-1 & 0.871 & 0.72 & 1 \\
Generator-2 & 0.84 & 0.64 & 0.917 \\
Generator-3 & 0.532 & 0.32 & 0.466 \\
Generator-4 & 0.622 & 0.48 & 0.65 \\
Generator-5 & 0.24 & 0.16 & 0.15 \\
Generator-6 & 0.115 & 0.071 & 0 \\
\hline
\end{tabular}

Table 3. The order of $S_{j}, R_{j}, Q_{j}$ in economic dispatch problem

\begin{tabular}{cccc}
\hline Generators & $\begin{array}{c}\text { Order } \\
\left(\mathrm{S}_{\mathrm{j}}\right)\end{array}$ & $\begin{array}{c}\text { Order } \\
\left(\mathrm{R}_{\mathrm{j}}\right)\end{array}$ & $\begin{array}{c}\text { Orde } \\
\mathrm{r} \\
\left(\mathrm{Q}_{\mathrm{j}}\right)\end{array}$ \\
\hline Generator-1 & 6 & 6 & 6 \\
Generator-2 & 5 & 5 & 5 \\
Generator-3 & 3 & 3 & 3 \\
Generator-4 & 4 & 4 & 4 \\
Generator-5 & 2 & 2 & 2 \\
Generator-6 & 1 & 1 & 1 \\
\hline
\end{tabular}

According to the economic dispatch problem result, it is seen that condition 2 is satisfied but condition 1 is not satisfied because difference between the best option and the option that is the closest one to the best option does not satisfy Equation 9. Therefore, Generator 5 that does not satisfy the inequality that is mentioned in condition 1 is taken as the last order in the decision. The value of $R_{j}$ are taken as a coefficient because $Q_{j}$ has the zero value that cost can not be calculated. For 500 MW load approximately $247 \mathrm{MW}$ for Generator 6, $110 \mathrm{MW}$ for Generator 3, $55 \mathrm{MW}$ for Generator 4, 37 MW for Generator 2, 27 MW for Generator 1, and $24 \mathrm{MW}$ for Generator 5 are taken as generated powers. From these results, the fuel cost (FC) is calculated as 27593 \$/hour. When the load is dispatched in terms of economy, the amount of emission (E) is obtained as $382.4821 \mathrm{~kg} /$ hour. The economic dispatch results are shown in Table 4

Table 4. The economic dispatch results

\begin{tabular}{|c|c|c|}
\hline Symbol & Value & Unit \\
\hline P1 & 27 & MW \\
\hline P2 & 37 & MW \\
\hline P3 & 110 & MW \\
\hline P4 & 55 & MW \\
\hline P5 & 24 & MW \\
\hline P6 & 247 & MW \\
\hline FC & 27593 & \$/hour \\
\hline E & 382.4821 & $\mathrm{~kg} /$ hour \\
\hline
\end{tabular}

In the solution of environmental dispatch problem, 6 generators are determined as decision points. The $\mathrm{NO}_{\mathrm{x}}$ emission coefficients of the system $(d, e, f)$ are established as the factors that affect the decision points. Firstly, values of $f_{i}$ are determined by considering emission coefficients. The decision matrix that consists of values of $f_{i}$ is obtained. While forming the decision matrix, the numbers from 1 to 10 are given as points to the elements of the matrix. The points are 
Ö. P. Akkaș et all. / Load Dispatch for a Power System in terms of Economy and Environment by Using VIKOR Method

determined by considering the values of emission coefficients for each generator. For example, the minimum value of emission coefficient $\mathrm{d}$ is for Generator 1 and Generator 2. It is benefit to take minimum value due to reduction of emission. Therefore, Generator 1 nad Generator 2 take the biggest point (10) among other generators for emission coefficient $d$. The maximum value of cost coefficient $d$ is for Generator 5 and Generator 6 so they take the smallest point (2) among other generators for emission coefficient $d$. The decision matrix for environmental dispatch problem is shown in Table 5.

Table 5. The values of fi for all criterion in environmental dispatch problem

\begin{tabular}{cccc}
\hline Generators & $\mathrm{a}$ & $\mathrm{b}$ & $\mathrm{c}$ \\
\hline Generator-1 & 10 & 2 & 10 \\
Generator-2 & 10 & 2 & 10 \\
Generator-3 & 2 & 10 & 5 \\
Generator-4 & 2 & 10 & 5 \\
Generator-5 & 5 & 5 & 2 \\
Generator-6 & 5 & 5 & 2 \\
\hline
\end{tabular}

As seen in Table 4, the maximum value of $f_{i}\left(f_{i}{ }^{*}\right)$ is 10 and minimum value of $f_{i}\left(f_{i}{ }^{-}\right)$ is 2 . These values are taken in the calculations.

The values of $S_{j}, R_{j}$, and $Q_{j}$ that are mentioned in Step 2 and Step 3 are calculated by using Equation 6, Equation 7, and Equation 8. The weights of criterion are taken from the study [16]. In study [16], the values of criterion for the same power system that is used in this study are obtained by Analytical Hierarchy Process (AHP) method. According to it, the weights of criterion (cost coefficents d,e,f) are 0.08, 0.20 and 0.72 , respectively. The values of $S_{j}, R_{j}$, and $Q_{j}$ and order in environmental dispatch problem are shown in Table 6 and Table 7 , respectively.
Table 6. The values of $S_{j}, R_{j}, Q_{j}$ in environmental dispatch problem

\begin{tabular}{cccc}
\hline Generators & $\mathrm{S}_{\mathrm{j}}$ & $\mathrm{R}_{\mathrm{j}}$ & $\mathrm{Q}_{\mathrm{j}}$ \\
\hline Generator-1 & 0.2 & 0.125 & 0 \\
Generator-2 & 0.2 & 0.125 & 0 \\
Generator-3 & 0.53 & 0.45 & 0.47 \\
Generator-4 & 0.53 & 0.45 & 0.47 \\
Generator-5 & 0.895 & 0.18 & 1 \\
Generator-6 & 0.895 & 0.18 & 1 \\
\hline
\end{tabular}

Table 7. The order of $S_{j}, R_{j}, Q_{j}$ in environmental dispatch problem

\begin{tabular}{cccc}
\hline Generators & $\begin{array}{c}\text { Order } \\
\left(\mathrm{S}_{\mathrm{j}}\right)\end{array}$ & $\begin{array}{c}\text { Order } \\
\left(\mathrm{R}_{\mathrm{j}}\right)\end{array}$ & $\begin{array}{c}\text { Order } \\
\left(\mathrm{Q}_{\mathrm{j}}\right)\end{array}$ \\
\hline Generator-1 & 1 & 1 & 1 \\
Generator-2 & 1 & 1 & 1 \\
Generator-3 & 2 & 3 & 2 \\
Generator-4 & 2 & 3 & 2 \\
Generator-5 & 3 & 2 & 3 \\
Generator-6 & 3 & 2 & 3 \\
\hline
\end{tabular}

According to the environmental dispatch problem result, it is seen that condition 1 and condition 2 are satisfied. The value of $\mathrm{Rj}$ are taken as a coefficient because $\mathrm{Qj}$ has the zero value that cost can not be calculated. For 500 MW load, approximately 127 MW for Generator 1 and Generator 2, 88 MW for Generator 5 and Generator 6, 35 MW for Generator 3 and Generator 4 are found as generated powers. From these results, the amount of emission (E) is calculated as 397.7193 $\mathrm{kg} /$ hour. When the load is dispatched in terms of environment, the fuel cost (FC) is obtained as 31517 \$/hour. The emission dispatch results are shown in Table 6.

Table 6. The emission dispatch results

\begin{tabular}{|c|c|c|}
\hline Symbol & Value & Unit \\
\hline P1 & 127 & MW \\
\hline P2 & 127 & MW \\
\hline P3 & 88 & MW \\
\hline P4 & 88 & MW \\
\hline P5 & 35 & MW \\
\hline P6 & 35 & MW \\
\hline FC & 31517 & $\$ /$ hour \\
\hline E & 397.7193 & $\mathrm{~kg} /$ hour \\
\hline
\end{tabular}


Ö. P. Akkaș et all. / Load Dispatch for a Power System in terms of Economy and Environment by Using VIKOR Method

\section{Discussion and Conclusion}

In this study, VIKOR method is used to solve economic and environmental dispatch problems. It is obtained that VIKOR method is not used about power systems. Therefore, VIKOR method is chosen in the solution of economic and environmental load dispatch problems. These problems are solved in 6 generators test system. In economic dispatch problem, generation cost is calculated as 27593 \$/hour and the amount of emission is calculated as $382.4821 \mathrm{~kg} /$ hour. In environmental dispatch problem, the amount of emission is calculated as 372.416 $\mathrm{kg} /$ hour and generation cost is calculated as $31517 \$ /$ hour. When the results of economic and environmetal dispatch problems are compared, it is obtained that economic dispatch has lower generation cost of 3924 \$/hour than environmental dispatch. However, emission levels of environmetal dispatch are better than economic dispatch by $10.0661 \mathrm{~kg} /$ hour.

\section{References}

[1] Chen, F., Huang, G.H., Fan, Y.R., Liao, R.F. 2016. A Nonlinear Fractional Programming Approach for Environmental-economic Power Dispatch, Electrical Power and Energy Systems, 78, 2016, p. 463469.

[2] Abdelaziz, A.Y., Ali, E.S., Abd Elazim , S.M. 2016. Combined Economic and Emission Dispatch Solution Using Flower Pollination Algorithm, Electrical Power and Energy Systems, 80, 2016, p. 264-274.

[3] Bhattacharjee, K., Bhattacharya, A., Dey, S.H. 2015. Backtracking Search Optimization Based Economic Environmental Power Dispatch Problems, Electrical Power and
Energy Systems, 73, 2015, p. 830 842.

[4] Rajan, A., Malakar, T. 2016. Optimum Economic and Emission Dispatch Using Exchange Market Algorithm, Electrical Power and Energy Systems, 82, 2016, p. 545-560.

[5] Fadıl, S., Urazel, B. 2014. A Security Constrained Environmental/economic Power Dispatch Technique Using F-MSG Algorithm for a Power System Area Including Limited Energy Supply Thermal Units, Electrical Power and Energy Systems, 56, 2014, p. 185 197.

[6] Rugthaicharoenchep, N., Thongkeaw, S. 2012. Economic Load Dispatch with Daily Load Patterns Using Particle Swarm Optimization, Journal of Energy and Power Engineering, 6, 2012, p. 1718-1724.

[7] Sen, T., Hitesh, D.M. 2016. A New Approach to Solve Economic Dispatch Problem Using a Hybrid ACO-ABC-HS Optimization Algorithm, Electrical Power and Energy Systems, 78, 2016, p. 735744.

[8] Dosoglu, M.K., Guvenc, U., Sonmez, Y., Kahraman, H.T. 2016. Symbiotic Organisms Search Optimization Algorithm for Economic/Emission Dispatch Problem in Power Systems, Neural Computing \& Applications, 2016, p. 1-17. DOI: 10.1007/s00521-016-2481-7

[9] Hota, P.K., Sahu, N.C. 2015. Security Constrained Economic Environmental Dispatch Through Fuzzy Based Gravitational Search Algorithm, American Journal of Electrical and Electronic 
Ö. P. Akkaş et all. / Load Dispatch for a Power System in terms of Economy and Environment by Using VIKOR Method

Engineering, Vol. 3, No. 2, p. 44-50. DOI: 10.12691/ajeee-3-2-4

[10] Bansal, S., Verma, S., Singh, S.K. 2015. Identification of Sustainability Indicators and Evaluation of Transportation Corridors during Construction Using Fuzzy VIKOR Method, Journal of Civil Engineering and Architecture, 9, 2015, p. 12171228.

[11] Mohanty, P.P., Manapata, S.S. 2014. A Compromise Solution by VIKOR Method for Ergonomically Designed Product with Optimal Set of Design Characteristics, 3rd International Conference on Materials Processing and Characterization, Procedia Material Science, 6, 2014, p. 633640.

[12] Modiri-Delshad, M., Abd Rahim, N. (2016. Multi-objective Backtracking Search Algorithm for Economic Emission Dispatch Problem, Applied Soft Computing, 40, 2016, p. 479494.

[13] Gul, M., Celik, E., Aydin, N., Gumus, A.T., Guneri, A.F. 2016. A State of the Art Literature Review of VIKOR and Its Fuzzy Extensions on Applications, Applied Soft Computing, 46, 2016, p. 60-89.

[14] Zhang, N., Wei, G. 2013. Extension of VIKOR Method for Decision Making Problem Based on Hesitant Fuzzy Set, Applied Mathematical Modelling, 37, 2013, p. 4938-4967.

[15] Rughooputh, H.C.S, Ah King, R.T.F. (2013. Environmental/Economic Dispatch of Thermal Units using an Elitist Multiobjective Evolutionary Algortihm, ICIT, Maribor, Slovenia, 2013.

[16] Akkas, Ö.P., Arıkan, Y., Çam, E. 2016. Economic and Environmental
Dispatch of Power Systems by Using Analytic Hierachy Process (AHP) Method, 8th Ege Energy Symposium, May 11-13, 2016, Afyonkarahisar. 